\title{
The Potential of Probiotics to Eradicate Gut Carriage of Pathogenic or Antimicrobial-Resistant Enterobacterales
}

\author{
Yuan-Pin Hung 1,2,+(D), Ching-Chi Lee ${ }^{2,3,+} \mathbb{D}$, Jen-Chieh Lee ${ }^{2}$, Pei-Jane Tsai ${ }^{4,5,6}$, Po-Ren Hsueh ${ }^{7, *}$ \\ and Wen-Chien Ko $2,8, *$ (i)
}

Citation: Hung, Y.-P.; Lee, C.-C.; Lee, J.-C.; Tsai, P.-J.; Hsueh, P.-R.; Ko, W.-C. The Potential of Probiotics to

Eradicate Gut Carriage of Pathogenic or Antimicrobial-Resistant Enterobacterales. Antibiotics 2021, 10, 1086. https://doi.org/10.3390/ antibiotics10091086

Academic Editor: Dóra Szabó

Received: 23 August 2021

Accepted: 6 September 2021

Published: 8 September 2021

Publisher's Note: MDPI stays neutral with regard to jurisdictional claims in published maps and institutional affiliations.

Copyright: (c) 2021 by the authors. Licensee MDPI, Basel, Switzerland. This article is an open access article distributed under the terms and conditions of the Creative Commons Attribution (CC BY) license (https:/ / creativecommons.org/licenses/by/ $4.0 /)$.
1 Department of Internal Medicine, Tainan Hospital, Ministry of Health and Welfare, Tainan 700, Taiwan; yuebin16@yahoo.com.tw

2 Department of Internal Medicine, College of Medicine, National Cheng Kung University Hospital, National Cheng Kung University, Tainan 704, Taiwan; chichingbm85@yahoo.com.tw (C.-C.L.); jclee.eric@msa.hinet.net (J.-C.L.)

3 Clinical Medicine Research Center, College of Medicine, National Cheng Kung University Hospital, National Cheng Kung University, Tainan 704, Taiwan

4 Department of Medical Laboratory Science and Biotechnology, College of Medicine, National Cheng Kung University, Tainan 705, Taiwan; peijtsai@mail.ncku.edu.tw

5 Institute of Basic Medical Sciences, College of Medicine, National Cheng Kung University, Tainan 705, Taiwan

6 Department of Pathology, National Cheng Kung University Hospital, National Cheng Kung University, Tainan 704, Taiwan

7 Departments of Laboratory Medicine and Internal Medicine, China Medical University Hospital, School of Medicine, China Medical University, Taichung 404, Taiwan

8 Department of Medicine, College of Medicine, National Cheng Kung University, Tainan 705, Taiwan

* Correspondence: hsporen@gmail.com (P.-R.H.); winston3415@gmail.com (W.-C.K.)

+ These authors contribute equally.

Abstract: Probiotic supplements have been used to decrease the gut carriage of antimicrobial-resistant Enterobacterales through changes in the microbiota and metabolomes, nutrition competition, and the secretion of antimicrobial proteins. Many probiotics have shown Enterobacterales-inhibiting effects ex vivo and in vivo. In livestock, probiotics have been widely used to eradicate colon or environmental antimicrobial-resistant Enterobacterales colonization with promising efficacy for many years by oral supplementation, in ovo use, or as environmental disinfectants. In humans, probiotics have been used as oral supplements for infants to decease potential gut pathogenic Enterobacterales, and probiotic mixtures, especially, have exhibited positive results. In contrast to the beneficial effects in infants, for adults, probiotic supplements might decrease potentially pathogenic Enterobacterales, but they fail to completely eradicate them in the gut. However, there are several ways to improve the effects of probiotics, including the discovery of probiotics with gut-protection ability and antimicrobial effects, the modification of delivery methods, and the discovery of engineered probiotics. The search for multifunctional probiotics and synbiotics could render the eradication of "bad" Enterobacterales in the human gut via probiotic administration achievable in the future.

Keywords: probiotics; synbiotics; antimicrobial-resistant; Enterobacterales; gastrointestinal tract; livestock

\section{Introduction}

Trillions of bacteria colonize in various anatomical locations in the human body, including the mouth, the upper airways, the skin, the vagina, the genitourinary system, and the intestinal tract. These colonized locations represent a highly integrated ecosystem collectively called "microbiota" [1,2]. Thus, humans are considered to be metaorganisms (also termed superorganisms or holobionts) [1,2]. The overlap of the phylogenetic trees of bacterial microbiota and primates suggests the coevolution, especially the genetic coevolution, between host and microbiota [2-4]. The microbial colonization of the human body starts immediately following birth, and the community composition is shaped by 
various environmental factors [5]. The infant gut microbiota is mostly predominated by the members of Actinobacteria, Proteobacteria, Firmicutes, and Bacteroidetes [5]. Factors influencing microbiome composition and diversity include the mode of delivery, the feeding type, maternal antibiotic and probiotic use, dietary intake, pre-pregnancy body mass index, gestational weight gain, diabetes mellitus, mood, and others [6]. For example, vaginally delivered (SVD) and breast-fed (BF) infants had a higher abundance of gut microbiota than caesarean-section-delivered, milk-powder-fed, and mixed-fed infants [7]. The genera Enterobacterales and Bifidobacterium were highly abundant in the SVD and BF groups [7]. Prior antibiotic therapy was independently associated with the carriage of extended-spectrum $\beta$-lactamase (ESBL)-producing Enterobacterales in an infant cohort upon admission to a tertiary teaching hospital in France [8]. Moreover, neonatal enteral tube feeding has been noted to serve as loci for colonization by the members of Enterobacterales [9]. Although established during infancy, the complex gut microbial community will be shaped by further medical interventions and societal preferences, such as caesarean section, formula feeding, and antibiotic use [10].

The microbiota in the gut of patients with diseases or who are aging, compared to the relative healthy population, is characterized by a decrease in diversity, greater interindividual variability, fewer beneficial microbes, such as the Firmicutes, Bifidobacterium, and Clostridium species and Faecalibacterium prausnitzii, and more pathogenic Enterobacterales [11]. The carriage of Enterobacterales in the gut is associated with lower phylogenetic diversity, dysbiotic microbiota, and the depletion of anaerobic commensals in the gut microbiota [12,13]. Moreover, among persons with gut colonization by carbapenem-resistant Enterobacterales (CRE), compositional and functional changes in the microbiota are linked to an increased risk in subsequent systemic infection and bacteremia [12].

The prevalence rate of antimicrobial-resistant organisms (AMROs), including ESBLproducing Escherichia coli and CRE, has increased in recent years [14]. Fortunately, these AMROs have been suppressed by the supernatant of some probiotics, such as Clostridium butyricum, Enterococcus faecium, and Lactobacillus plantarum, in a dose-dependent manner ex vivo [15]. Thus, it has been suggested that oral probiotic supplements can be used to eradicate Enterobacterales colonization in the gut.

Oral antibiotics, probiotics, and fecal microbiota transplantation have recently been analyzed for their potential use in decolonizing ESBL-producing Enterobacterales or CRE in the gut over the past 10 years [16]. However, in a review in 2019, Gaud Catho et al. suggest that there is not enough available evidence to recommend these decolonization strategies for the intestinal carriage of antimicrobial-resistant Enterobacterales in routine clinical practice [16]. Although the results of the routine clinical practice of probiotics in eradicating the gut carriage of antimicrobial-resistant Enterobacterales were inconclusive before 2019, many subsequent ex vivo, in vivo, and animal studies are now ongoing [17-23].

\subsection{Rationale for Probiotic Supplements to Eradicate Enterobacterales Carriage in the Gut}

Probiotics, by definition, are live microorganisms, and should remain viable when they reach the intended site of action, which is typically the cecum and/or the colon [24]. Most probiotics originate from fermenting food, an ancient form of preservation ingrained in human societies around the world [25]. The microbiome of all fermented foods shows increasing amounts of Lactobacillales during the fermentation process, which replaces the initial dominant composition of Enterobacterales in these foods [25]. The incorporation of probiotics into food results in higher counts of lactic acid-producing bacteria and lower counts of Enterobacterales [26]. To date, probiotics have been widely used as food additives.

The eradication of pathogenic Enterobacterales by supplementation with probiotics has been confirmed in several animal models [17-20,23]. Mice pretreated with B. bifidum ATCC 29521 exhibited a significant increase in the diversity of the gut microbiome, and a decrease in the abundance of the genus Escherichia-Shigella, belonging to the family Enterobacterales [17]. These changes in microbiota after B. bifidum ATCC 29521 pretreatment were associated with a decrease in the severity of inflammatory bowel disease [17]. More- 
over, L. rhamnosus GG could reduce the mortality rate of septic mice by modulating gut microbiota composition, especially reducing the lipopolysaccharide producers, such as Enterobacterales [18]. Bacillus coagulans SANK 70258 suppressed Enterobacterales and enhanced butyrogenesis in microbiota models [19]. L. plantarum, isolated and identified from yak yogurt, increased the content of beneficial bacteria, including Bacteroides, Bifidobacterium, and Lactobacillus, and reduced the content of harmful bacteria, including Firmicutes, Actinobacteria, Proteobacteria, and Enterobacterales, and, thus, could protect against alcoholic liver injury [20]. The oral administration of L. rhamnosus GG can improve the survival rate of mice with sepsis by reducing lipopolysaccharide-producing Enterobacterales, decreasing epithelial apoptosis, and increasing the proliferation of colonic epithelium and the expression of tight junction proteins [23]. A mixture of probiotics showed more efficient eradication of pathogenic Enterobacterales in vivo. In mice, the mixture of L. fermentum GOS47 and L. fermentum GOS1 significantly decreased the viable count of Enterobacterales with potential anti-inflammatory activity and short-chain fatty acid production [27]. Thus, the favorable effect of probiotic supplements on at least the partial elimination of pathogenic Enterobacterales, ex vivo and in vivo, has promoted their application in clinical diseases.

Supplementation with probiotics has been investigated for the alleviation of the disease severity of systemic or gastrointestinal inflammatory diseases, such as sepsis, inflammatory bowel disease, and chemotherapy- or radiation-induced gastrointestinal mucositis [17-19,28,29]. For example, patients receiving cytotoxic and radiation therapy showed striking alterations in intestinal microbiota with, most frequently, a decrease in Bifidobacterium, Clostridium cluster XIVa and F. prausnitzii, and an increase in Enterobacterales and Bacteroides [28]. These pathogenic alterations resulted in the development of mucositis and bacteremia $[28,29]$. The prevention of cytotoxic chemotherapy-induced mucositis by probiotics has been investigated in randomized clinical trials with some promising results. Moreover, in a meta-analysis of randomized controlled trials with patients undergoing a colorectal resection, the perioperative administration of probiotics or synbiotics was associated with increased numbers of Lactobacillus and decreased counts of Enterobacterales [30]. These changes in gut microbiota were associated with less diarrhea, less symptomatic intestinal obstruction, and a lower incidence of total postoperative infections [30]. Accordingly, the use of probiotics in modulating gut microbiota and decreasing pathogenic Enterobacterales has become popular for application in many bowel or extra-bowel diseases, and more extensive probiotic usage can be expected in the future.

\subsection{Probiotic Supplements to Decrease Gut Carriage of Enterobacterales in Livestock or Domesticated Animals}

The use of probiotics in preventing gut Enterobacterales colonization has been applied in livestock breeding [31-36]. Lactobacillus supplementation, in directly fed microbes or used as phytobiotic feed additives, reduced the prevalence of ESBL-producing Enterobacterales in broilers [31]. In young broilers, the neonatal colonization of Enterobacterales strains led to immune dysregulation and chronic inflammation, but early life exposure to a mixture of probiotics containing lactic-acid-producing bacteria could modulate the immune functions through the activation and trafficking of immune cells [32]. In weaned piglets, B. subtilis DSM25841 treatment reduced enterotoxigenic E. coli (ETEC) F4 infection and decreased the risk of diarrhea [34]. L. reuteri KUB-AC5 possessed antimicrobial activity in reducing Salmonella contamination in live poultry [35]. The above data further support the use of probiotics as feed additives in livestock breeding.

Other than oral intake, the in ovo administration of probiotics for eradicating gut Enterobacterales colonization has been used in chickens [37,38]. Via the in ovo route during hatching, a Bacillus-based probiotic (BPP) can reduce the severity of the virulent E. coli horizontal transmission among broiler chickens, which might be achieved by alterations in the microbiota composition, including a decrease in Enterobacterales and an increase in Lachnospiraceae [37]. In another chicken study, the in ovo administration of lacticacid-producing bacteria resulted in an increased abundance in the Lactobacillaceae family and Lactobacillus genus, and a decrease in Enterobacterales and Enterococcaceae [38]. For 
bird species, the early in ovo administration of probiotics seems to be more efficient in eradicating gut Enterobacterales colonization before hatching.

A mixture of probiotics may work better to eradicate gut Enterobacterales in livestock breeding [33,39-41]. The administration of multistrain probiotics containing L. acidophilus LAP5, L. fermentum P2, Pediococcus acidilactici LS, and L. casei L21 could modulate intestinal microbiota (increase Lactobacillaceae abundance and reduce Enterobacterales abundance), increase the gene expression of tight junction proteins (ZO-1 and Mucin 2) and the immunomodulatory activity (downregulation of mRNA levels of interferon- $\gamma$ [IFN- $\gamma]$ and lipopolysaccharide-induced tumor necrosis factor- $\alpha$ [TNF- $\alpha]$, and upregulation of IL-10) in broiler chickens [33]. Commercially available synbiotics, either BioPlus $2 \mathrm{~B}^{\circledR}$ or Cylactin ${ }^{\circledR}$ LBC, had a more significant impact on the concentration of lactic acid, short-chain fatty acids (SCFAs), and branched-chain fatty acids (BCFAs), than a single probiotic in sows [39]. Mixed probiotics composed of three thermophilic lactic-acid-producing bacteria (LAB) strains, L. helveticus BGRA43 (strong proteolytic activity, antimicrobial activity, and adhesion to gut cell activity), L. fermentum BGHI14 (immunomodulatory effect), and Streptococcus thermophiles BGVLJ1-44 (strong proteolytic activity and immunomodulatory effect), influenced the colonization of piglet guts with beneficial bacteria, and reduced the number of Enterobacterales in some treated sows [41]. Thus, the commercially available mixed regimens of probiotics may be more efficient in eliminating Enterobacterales carriage in the guts of livestock.

Furthermore, probiotics in combination with prebiotics (foods that promote the growth of beneficial microbes), or phytobiotics (plant-derived products), have been utilized in livestock breeding for the eradication of gut colonization by Enterobacterales [40,42]. Lactobacillus strains (L.agilis and L. salivarius), combined with phytobiotics, have been used to reduce the survival of potentially problematic bacteria, such as ESBL-producing E. coli in broilers [42]. The synbiotics (L. rhamnosus HN001 and P. acidilactici) combined with the phytobiotics (Agave tequilana fructans) induced morphological modifications in the duodenal mucosa of broilers that, in turn, promoted resistance to infections caused by S. typhimurium and C. perfringens [40].

In addition, a probiotic-based cleaning strategy to decontaminate Enterobacterales in livestock environments has been reported [43]. The cleaning product, containing $B$. subtilis, B. pumilus, and B. megaterium spores, was used to clean fresh and reused broiler litters [43]. These Bacillus spores were able to successfully colonize reused poultry litters to decrease the mean counts of total aerobic bacteria, Enterobacterales, and coagulasepositive Staphylococcus [43]. A decrease in Enterobacterales, mainly the genus Escherichia, was also observed in the ceca of broilers reared on reused litters treated with the cleaning product [43]. The efficacy and safety issues of this probiotic-based cleaning product are still ongoing for livestock environments, but have not been tested for human environments.

Among domesticated animals, such as weaning rabbits, L. buchneri could decrease Enterobacterales counts in the gut and upregulate anti-inflammatory interleukin (IL)- 4 and the expression of intestinal barrier-related genes, such as zonula occludens-1 (ZO-1), and, thus, may prevent diarrhea [36]. In a randomized controlled trial of healthy cats, Enterobacterales declined after the administration of synbiotics, a combination of probiotics (Proviable-DC ${ }^{\circledR}$ containing E. faecium, B. bifidum, E. thermophilus, L. acidophilus, L. bulgaricus, L. casei, and L. plantarum) [21]. Among dogs fed Queso Blanco cheese with B. longum KACC 91563 for eight weeks, a reduction in harmful bacteria, such as the Enterobacterales and Clostridium species, was noted [22]. The successful decrease in Enterobacterales after probiotic supplementation in pet animals arouses hope for the eradication of gut Enterobacterales carriage via the use of probiotics in humans.

\subsection{The Selection of Probiotics to Decrease Gut Colonization of Enterobacterales in Humans}

The common, safe, and well-studied probiotics used to eradicate the gut carriage of Enterobacterales in humans include the Lactobacillus [44-47] and Bifidobacterium [17,47,48] species. In extremely low-birth-weight infants, L. reuteri supplementation for one week 
resulted in a lower abundance of Enterobacterales and Staphylococcaceae [44]. Among infants fed B. infantis EVC001, a high abundance of Bifidobacteriaceae developed rapidly with a reduced abundance of antibiotic-resistant genes among Enterobacterales and/or Staphylococcaceae [48].

As noted in livestock, probiotic mixtures might provide better protection against gut Enterobacterales colonization than a single probiotic regimen in humans [45,49-51]. A probiotic mixture (Bactiol duo ${ }^{\circledR}$ ) containing Saccharomyces boulardii, L. acidophilus NCFM, L. paracasei Lpc-37, B. lactis Bl-04, and B. lactis Bi-07, provides better eradication of AmpCproducing Enterobacterales carriage than $S$. boulardii CNCM I-745 ${ }^{\circledR}$ [45]. Oral daily supplementation with a combination of a prebiotic $\left(\right.$ Emportal $^{\circledR}$ : lactitol) and probiotics (Infloran ${ }^{\circledR}$ : B. bifidum and L. acidophilus) for three weeks decreased the intestinal load of OXA-48producing Enterobacterales among eight patients with long-term intestinal carriage [49]. Moreover, the ingestion of combined probiotics containing L. plantarum LK006, B. longum LK014, and B. bifidum LK012 could significantly reduce the abundance of Enterobacterales and increase the abundance of Lactobacillaceae in preterm infants [50]. These changes in microbiota were correlated with a decreased serum inflammatory cytokine level of IL-6 and improved the survival rate of these infants. A mixture of B. breve M-16V, B. longum subsp. infantis (B. infantis) M-63, and B. longum subsp. longum BB536, achieved significantly higher levels of Bifidobacterium-predominant microbiota and lower detection rates for Clostridium and Enterobacterales than a single B. breve strain [51]. For human safety, the most common probiotics for combination are the Lactobacillus and Bifidobacterium species.

\subsection{Probiotic Supplementation to Decrease Potential Gut Pathogenic Enterobacterales from Infants to Children}

Probiotics have been used as supplements for infants to decease potential gut pathogenic Enterobacterales [44,48,50,52-57] (Table 1). Among hospitalized infants, early administration of L. reuteri DSM 17938 was associated with less colonization by diarrheagenic E. coli [55]. In a randomized placebo-controlled study that administered B. infantis to 24 infants with gastroschisis, the microbial communities were not significantly influenced [52]. In a doubleblind, placebo-controlled randomized clinical study conducted on 69 preterm infants, B. lactis BB-12 supplementation resulted in lower viable counts of Enterobacterales [57]. Moreover, in a randomized trial of 300 healthy newborns, the receipt of B. longum BB536 was associated with a higher Bifidobacterium/Enterobacterales ratio (B/E), an increased number of IFN- $\gamma$-secreting cells, and a higher ratio of IFN- $\gamma /$ IL-4-secreting cells, which is indicative of the increased Th1 response [54]. Among 21 neonates that underwent surgery for congenital heart disease $>7$ days after birth, the enteral B. breve strain Yakult (BBG-01) supply led to significantly fewer Enterobacterales in the gut [56]. Since infants, especially preterm infants, are susceptible to intestinal infection, many probiotic studies have been conducted on these susceptible hosts that have provided promising results against pathogenic Enterobacterales colonization in the gut.

However, not all studies have shown the presence of the beneficial effects of the addition of probiotics for infants. In a double-blind randomized control trial, 21 bottle-fed preterm infants receiving L. rhamnosus GG did not show a decrease in the numbers of Enterococcus and Enterobacterales in the gut, increased weight gain, or a decreased hospital stay compared to 26 control infants [58]. In an early review of randomized controlled trials including preterm infants, the $B$. animalis subsp. lactis supplement could increase fecal Bifidobacterium counts and reduce Enterobacterales and Clostridium counts, but it did not influence the risk of necrotizing enterocolitis or sepsis [59]. The diverse inhibitory potential of Enterobacterales, and the microbiota-modulating effect of probiotics, are likely due to the intrinsic diversity of the gut microbiota of infants and children inhabiting different areas [60]. 
Table 1. Probiotic supplements for infants and children to decease potential pathogenic Enterobacterales in the gut.

\begin{tabular}{|c|c|c|c|c|c|c|}
\hline $\begin{array}{l}\text { First } \\
\text { Author }\end{array}$ & Country & $\begin{array}{l}\text { Publish } \\
\text { Year }\end{array}$ & $\begin{array}{c}\text { Patient } \\
\text { Population/Number }\end{array}$ & Probiotics & $\begin{array}{l}\text { Main Findings after Probiotic } \\
\text { Supplementation }\end{array}$ & References \\
\hline Mohan R & Germany & 2006 & Preterm infants / 69 & $\begin{array}{l}\text { Bifidobacterium lactis } \\
\text { Bb12 }\end{array}$ & $\begin{array}{l}\text { Lower viable counts of } \\
\text { Enterobacterales }\end{array}$ & [57] \\
\hline $\begin{array}{l}\text { Chrzanowska- } \\
\text { Liszewska D }\end{array}$ & Poland & 2012 & Bottle fed preterm/60 & $\begin{array}{l}\text { Lactobacillus } \\
\text { rhamnosus GG (LGG) }\end{array}$ & $\begin{array}{l}\text { Increase number of Enterobacterales } \\
\text { in gut }\end{array}$ & [58] \\
\hline Umenai T & Japan & 2014 & $\begin{array}{l}\text { Neonates undergoing } \\
\text { cardiac surgery } / 21\end{array}$ & $\begin{array}{l}\text { B. breve strain Yakult } \\
\text { (BBG-01) }\end{array}$ & $\begin{array}{l}\text { Significantly fewer Enterobacterales } \\
\text { in gut }\end{array}$ & [56] \\
\hline Savino F & Italy & 2015 & Hospitalized infant/60 & L. reuteri DSM 17938 & $\begin{array}{l}\text { Less colonization by diarrheagenic } \\
\text { E. coli. }\end{array}$ & [55] \\
\hline Wang C & Japan & 2015 & $\begin{array}{l}\text { In preschool and } \\
\text { school-age children } / 23\end{array}$ & L. casei strain Shirota & $\begin{array}{l}\text { Increased population levels of } \\
\text { Bifidobacterium and total } \\
\text { Lactobacillus, decreased } \\
\text { Enterobacterales, Staphylococcus and } \\
\text { Clostridium perfringens }\end{array}$ & [53] \\
\hline Wu BB & China & 2016 & Healthy newborns /300 & B. longum BB536 & $\begin{array}{c}\text { Higher } \\
\text { Bifidobacterium/Enterobacterales } \\
\text { ratio and increased the ratio of } \\
\text { IFN- } \gamma / \text { IL- } 4 \text { secretion cells }\end{array}$ & [54] \\
\hline Powell WT & USA & 2016 & Infants / 24 & $\begin{array}{l}\text { B. longum subsp. } \\
\text { infantis }\end{array}$ & $\begin{array}{c}\text { Overall, microbial communities } \\
\text { were not significantly influenced, } \\
\text { with trends only toward lower } \\
\text { Enterobacterales }\end{array}$ & [52] \\
\hline $\mathrm{Li} \mathrm{YF}$ & China & 2019 & $\begin{array}{l}\text { Low birth weight } \\
\text { infants } / 36\end{array}$ & $\begin{array}{l}\text { L. plantarum LK006, B. } \\
\text { longum LK014, and B. } \\
\text { bifidum LK012 }\end{array}$ & $\begin{array}{l}\text { Increase in Streptococcaceae and } \\
\text { Lactobacillaceae and decrease in } \\
\text { Enterobacterales }\end{array}$ & [50] \\
\hline Nguyen M & USA & 2021 & Infants/77 & B. infantis & $\begin{array}{l}\text { Reduced abundance of antibiotic } \\
\text { resistance genes among } \\
\text { Enterobacterales and } \\
\text { Staphylococcaceae }\end{array}$ & [48] \\
\hline Martí M & Sweden & 2021 & First month/132 & L. reuteri & $\begin{array}{l}\text { Lower abundance of } \\
\text { Enterobacterales and } \\
\text { Staphylococcaceae }\end{array}$ & [44] \\
\hline
\end{tabular}

\subsection{Probiotic Supplementation to Decrease Gut Pathogenic or Antimicrobial-Resistant Enterobacterales Colonization in Adults}

Among adults, probiotic supplements have been shown to decrease, but have failed to totally eradicate, potential antimicrobial-resistant or pathogenic Enterobacterales in the gut [45,47,61-66] (Table 2). To eradicate potential antimicrobial-resistant Enterobacterales, a clinical trial of a probiotic mixture (Bactiol duo ${ }^{\circledR}:$ S. boulardii, L. acidophilus NCFM, L. paracasei Lpc-37, B. lactis B1-04, and B. lactis Bi-07) showed that colonization with AmpCproducing Enterobacterales transiently increased after amoxicillin-clavulanate therapy and declined after probiotic intervention [45]. To eradicate potential pathogenic Enterobacterales in human-immunodeficiency-virus-infected individuals, L. rhamnosus GG supplementation was used and resulted in a decrease in intestinal inflammation, along with a reduction in Enterobacterales in the gut [62]. The consecutive intake of fermented soymilk (containing isoflavone) and L. casei Shirota among 60 healthy premenopausal Japanese women was able to decrease the fecal levels of Enterobacterales and to increase isoflavone bioavailability [63].

In contrast to the promising results of the probiotic trials on the eradication of potential antimicrobial-resistant Enterobacterales mentioned above, a randomized single-blind, placebo-controlled trial in southern Sweden used a probiotic mixture of eight living bacterial strains, Vivomixx ${ }^{\circledR}$, but the successful eradication of fecal ESBL-producing Enterobacterales carriage was rarely observed [47]. Among 31 Danish adults who traveled to India for 10-28 days, the ingestion of L. rhamnosus GG had no effect on the risk of ESBL-producing Enterobacterales colonization [61]. Of note, in 75 patients who underwent elective colon surgery, the oral intake of L. plantarum $299 \mathrm{v}$ for one week resulted in increased Enterobac- 
terales and Gram-negative anaerobes in the colon, but no change in the incidence of bacterial translocation or postoperative complications [66]. The diverse effect of probiotic supplements on gut Enterobacterales carriage is likely due to the different baseline gut microbiota and the decolonization efficacy of a variety of probiotic components. To date, probiotic supplementation is not routinely recommended to replace routine antibiotic decontamination in the preoperative preparation of the digestive tract [67]. However, probiotics or synbiotics might be used in combination with a conventional bowel preparation to reduce the fecal carriage of Enterobacterales [68]. However, the majority of larger-scale clinical trials show no evident clinical benefits, such as lower inflammatory responses, fewer infectious complications, or higher survival rates, among adults who consume probiotic supplements.

Table 2. Probiotic supplements for adults to decease potential pathogenic Enterobacterales in gut.

\begin{tabular}{|c|c|c|c|c|c|c|}
\hline $\begin{array}{l}\text { First } \\
\text { Author }\end{array}$ & Country & $\begin{array}{l}\text { Publish } \\
\text { Year }\end{array}$ & $\begin{array}{l}\text { Patient } \\
\text { Number }\end{array}$ & Probiotics & $\begin{array}{l}\text { Main Findings after Probiotic } \\
\text { Supplementation }\end{array}$ & References \\
\hline Mangell P & Sweden & 2012 & 75 & $\begin{array}{l}\text { Lactobacillus } \\
\text { plantarum } 299 \mathrm{v}\end{array}$ & $\begin{array}{l}\text { Increased Enterobacterales and Gram-negative } \\
\text { anaerobes in the colon } 1 \text { week after probiotics } \\
\text { without change in the incidence of bacterial } \\
\text { translocation and postoperative complications }\end{array}$ & [66] \\
\hline Larsen N & Denmark & 2013 & 50 & L. salivarius Ls-33 & $\begin{array}{l}\text { No significant influence on Clostridium cluster } \\
\text { I, Clostridium cluster IV, Faecalibacterium } \\
\text { prausnitzii, Enterobacterales, Enterococcus, the } \\
\text { Lactobacillus group, and Bifidobacterium }\end{array}$ & {$[65]$} \\
\hline Bajaj JS & USA & 2014 & 30 & L. rhamnosus GG & $\begin{array}{l}\text { Among cirrhotic patients with minimal hepatic } \\
\text { encephalopathy, reduced Enterobacterales and } \\
\text { increased Clostridiales Family XIV Incertae } \\
\text { Sedis and Lachnospiraceae relative abundance, } \\
\text { but no change in cognition }\end{array}$ & {$[64]$} \\
\hline Nagino $\mathrm{T}$ & Japan & 2018 & 60 & L. casei Shirota & $\begin{array}{l}\text { Consecutive intake of fermented soymilk } \\
\text { (containing isoflavone), and L. casei Shirota } \\
\text { decreased the levels of Enterobacterales }\end{array}$ & [63] \\
\hline Arnbjerg CJ & Denmark & 2018 & 45 & L. rhamnosus GG & $\begin{array}{l}\text { Decrease in intestinal inflammation, along with } \\
\text { a reduction of Enterobacterales in the gut } \\
\text { microbiome among human- } \\
\text { immunodeficiency-virus-infected individuals }\end{array}$ & {$[62]$} \\
\hline Dall LB & Denmark & 2019 & 31 & L. rhamnosus GG & $\begin{array}{l}\text { No effect on the risk of colonization with } \\
\text { extended spectrum } \beta \text {-lactamase } \\
\text { (ESBL)-Enterobacterales }\end{array}$ & [61] \\
\hline Ljungquist $\mathrm{O}$ & Sweden & 2020 & 80 & Vivomixx $^{\circledR 1}$ & $\begin{array}{l}\text { No support of Vivomixx }{ }^{\circledR} \text { as being superior to } \\
\text { the placebo for intestinal decolonization in } \\
\text { adult patients with chronic colonization of } \\
\text { ESBL-producing Enterobacterales }\end{array}$ & [47] \\
\hline Ramos-Ramos JC & Spain & 2020 & 8 & $\begin{array}{c}\text { B. bifidum and } L \text {. } \\
\text { acidophilus (Infloran }{ }^{\circledR} \text { ) }\end{array}$ & $\begin{array}{c}\text { Three weeks of a combination of prebiotics and } \\
\text { probiotics decreased the intestinal load of } \\
\text { OXA-48-producing Enterobacterales }\end{array}$ & [49] \\
\hline Wieërs G & Belgium & 2021 & 120 & Bactiol duo ${ }^{\circledR 2}$ & $\begin{array}{l}\text { Colonization with AmpC-producing } \\
\text { Enterobacterales declined after the } \\
\text { probiotic intervention }\end{array}$ & {$[45]$} \\
\hline
\end{tabular}

${ }^{1}$ contains 4 Lactobacillus strains (L. paracasei 24733, L. acidophilus 24735, L. delbrueckii subspecies bulgaricus 24734, and L. plantarum 24730), 3 Bifidobacterium strains (B. brief 24732, B. longum 24736, and B. infantis 24737), and S. thermophilus $24731 ;{ }^{2}$ contains S. boulardii, L. acidophilus NCFM, L. paracasei Lpc-37, B. lactis Bl-04, and B. lactis Bi-07.

\subsection{Possible Mechanisms by Which Probiotic Supplementation Decreases Gut Enterobacterales Carriage}

The decrease in gut Enterobacterales carriage after probiotic supplementation might be related to the increase in beneficial bacteria, such as Bacteroides, Bifidobacterium, and Lactobacillus [20,48,50], and SCFA-producing bacteria (such as Lachnospiraceae and Ruminococcaceae) [69], as well as to the changes in the metabolome in the gut (Figure 1) $[39,70]$. The continuous intake of a combination of probiotic cheese enriched with L. reuteri CCM 8617RIF and crushed flaxseed resulted in an alleviation of the infection course induced by 
pathogenic E. coli O149:F4NAL, favored n-3 polyunsaturated fatty acid metabolism, and inhibited n-6 PUFA metabolism in the gut [70]. Moreover, a probiotic mixture resulted in a greater increase in lactic acid, SCFAs, and branched-chain fatty acids (BCFAs), than a single probiotic in sows [39]. Conclusively, the gut metabolome changes after probiotic supplementation builds up an environment that is not friendly to Enterobacterales.

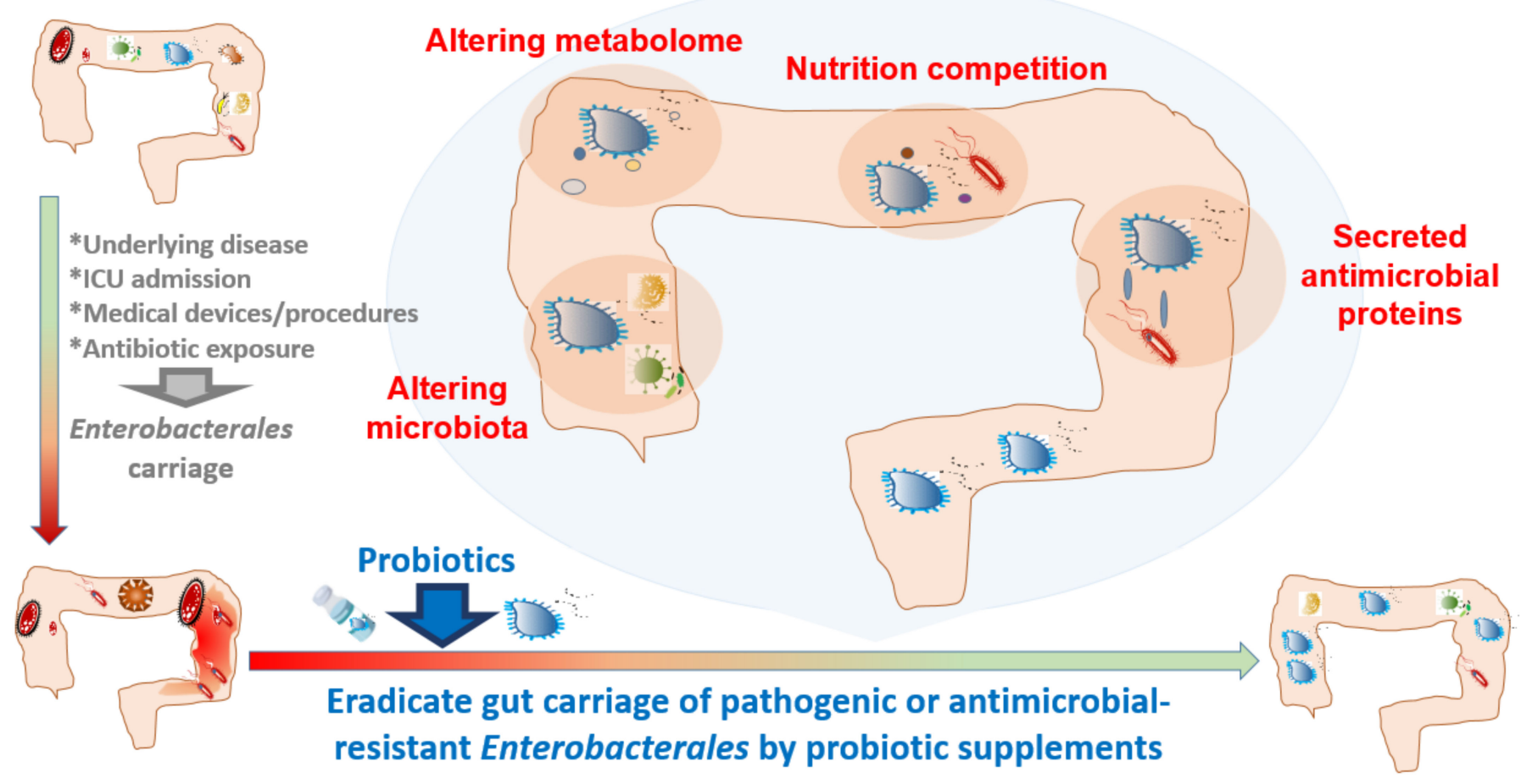

Figure 1. In humans, some clinical settings or interventions might promote intestinal carriage of Enterobacterales. Probiotics might be beneficial in eradicating gut carriage of pathogenic or antimicrobial-resistant Enterobacterales.

In addition, a microbe is regarded as a beneficial probiotic if it can secrete antimicrobial proteins targeting pathogenic Enterobacterales. For example, a probiotic strain, E. coli Nissle 1917, secretes small proteins called microcins that possess antimicrobial activity against pathogenic Enterobacterales during intestinal inflammation [71]. Therefore, probiotics capable of producing antimicrobial proteins might provide better Enterobacterales eradication efficacy. The Enterobacterales eradication capacity of probiotics can also result from the nutrition competition between probiotics and Enterobacterales. Commensal microbiota contributes to colonization resistance by competing with Salmonella enteritidis for oxygen, a resource critical for pathogen expansion [72]. An analysis of the complex nutrition competition in the microbiota of the gut provides an alternative method for selecting appropriate probiotics against Enterobacterales.

\subsection{Improve the Effect of Probiotics in Eradicating Enterobacterales}

Changes in the delivery method of probiotics might provide alternative ways of eradicate Enterobacterales in the gut [73]. Among patients with mild left-sided ulcerative colitis, the oral intake of L. casei DG failed to affect colonic flora, but the rectal administration of the same probiotics increased Lactobacillus spp. and reduced Enterobacterales, significantly decreased Toll-like receptor (TLR)-4 and IL-1 $\beta$ mRNA levels, and increased mucosal IL10 [73]. For probiotics vulnerable to gastric acid or intestinal enzymes, rectal administration might provide better efficacy for eradicating Enterobacterales in the gut.

Other than naturally found probiotics, engineered probiotics specifically targeting Enterobacterales have been investigated to improve gut colonization eradication. The introduction of genes with beneficial effects into probiotics provides additional effects, such as 
acid resistance, immune modulation, and gut barrier protection effects. A genetically engineered plasmid was delivered to E. coli that gained the capacity to produce tetrathionate which can inhibit the growth of Salmonella [74].

To facilitate the buildup of healthy gut microbiota, the ex vivo selection of appropriate probiotics is mandatory. Bacteriocin-producing bacteria capable of inhibiting bovine and wastewater $E$. coli isolates have been tested for their activity against Shiga toxin-producing E. coli, antimicrobial-resistant E. coli, and related enteric pathogens [75]. The selected bacteriocin-producing bacteria show potential as next-generation control strategies in livestock and humans. Another selected probiotic is B. infantis, a unique gut bacterium with a prodigious capacity to digest human milk oligosaccharides, that was specifically selected for the focused manipulation of infant intestinal microbiota [76].

\subsection{Clinical Trials of Probiotics or Synbiotics to Improve Gut Health}

There are three ongoing randomized clinical trials on dietary supplementation with probiotics aimed at gut Enterobacterales eradication registered at ClinicalTrials.gov, posted from July 2008 to July 2021 (Table 3) [77]. Commercial probiotic mixtures, synbiotics, are being applied in these three trials, and the commonly used probiotic strains include the Lactobacillus, Bifidobacterium, and Streptococcus species. Of note, one interesting trial is comparing the effects of gut Enterobacterales eradication between synbiotics and fecal microbiota transplantation.

Table 3. Three clinical trials of dietary supplementation with probiotics for the eradication of gut Enterobacterales carriage registered at ClinicalTrials.gov, as posted from July 2008 to July 2021.

\begin{tabular}{|c|c|c|c|c|c|c|c|}
\hline $\begin{array}{l}\text { ClinicalTrials.gov } \\
\text { Identifier }\end{array}$ & Official Title & First Posted & $\begin{array}{l}\text { Study } \\
\text { Design/Case } \\
\text { Number }\end{array}$ & $\begin{array}{l}\text { Probiotic } \\
\text { Strain }\end{array}$ & Location & Outcome Measures & Status \\
\hline NCT 00722410 & $\begin{array}{l}\text { Safety and efficacy study of } \\
\text { eradication of carbapenem- } \\
\text { resistant Klebsiella pneumoniae } \\
\text { from the gastrointestinal tract } \\
\text { by probiotics }\end{array}$ & 25 July 2008 & $\begin{array}{c}\text { Open-label, } \\
\text { randomized/60 }\end{array}$ & $\mathrm{VSL}^{\circledR}{ }^{\circledR 1}$ & $\begin{array}{l}\text { Jerusalem, } \\
\text { Israel }\end{array}$ & $\begin{array}{l}\text { Negative stool culture for } \\
\text { carbapenem-resistant } \\
\text { Klebsiella pneumoniae }\end{array}$ & $\begin{array}{l}\text { Not yet } \\
\text { recruiting }\end{array}$ \\
\hline NCT 03967301 & $\begin{array}{l}\text { Prevention and decolonization } \\
\text { of multidrug-resistant bacteria } \\
\text { with probiotics }\end{array}$ & 30 May 2019 & $\begin{array}{l}\text { Double-blinded, } \\
\text { randomized/228 }\end{array}$ & Bioflora ${ }^{\circledR 2}$ & $\begin{array}{l}\text { Buenos } \\
\text { Aires, } \\
\text { Argentina }\end{array}$ & $\begin{array}{l}\text { Risk of colonization } \\
\text { and/or infection by } \\
\text { carbapenem-resistant } \\
\text { Enterobacterales }\end{array}$ & $\begin{array}{l}\text { Not yet } \\
\text { recruiting }\end{array}$ \\
\hline NCT 04431934 & $\begin{array}{l}\text { Open-label, randomized study } \\
\text { to assess the efficacy of a } \\
\text { probiotic or fecal microbiota } \\
\text { transplantation (FMT) on the } \\
\text { eradication of rectal } \\
\text { multidrug-resistant } \\
\text { Gram-negative bacilli } \\
\text { (MDR-GNB) carriage } \\
\text { (PROFTMDECOL) }\end{array}$ & 16 June 2020 & $\begin{array}{c}\text { Open-label, } \\
\text { randomized/437 }\end{array}$ & Vivomixx $^{\circledR 3}$ & $\begin{array}{l}\text { Barcelona, } \\
\text { Spain }\end{array}$ & $\begin{array}{c}\text { Eradication of rectal } \\
\text { multidrug-resistant } \\
\text { Gram-negative bacilli } \\
\text { carriage }\end{array}$ & Recruiting \\
\hline
\end{tabular}

${ }^{1}$ VSL\# $3^{\circledR}: 4$ Lactobacillus strains (L. acidophilus, L. plantarum, L. casei, and the L. delbrueckii subspecies bulgaricus), 3 Bifidobacterium strains (B. breve, B. longum, and B. infantis), and the S. salivarius subspecies thermophilus; ${ }^{2}$ Bioflora ${ }^{\circledR}$ : L. casei, L. plantarum, S. faecalis, and B. brevis; ${ }^{3}$ Vivomixx $^{\circledR}: 4$ Lactobacillus strains (L. paracasei 24733, L. acidophilus 24735 , L. delbrueckii ssp bulgaricus 24734 , and L. plantarum 24730 ), 3 Bifidobacterium strains (B. brief 24732, B. longum 24736, and B. infantis 24737), and S. thermophilus 24731.

\subsection{Clinical Safety Issue of Probiotics}

Although the efficacy of probiotics in decreasing the gut carriage of Enterobacterales has been recognized, there are still concerns regarding their clinical safety, including potential infections or the inflammatory/fatal effects derived from toxins produced either by the probiotic strains or bacterial contaminants [78]. Lactobacillus infections after taking probiotic products containing the Lactobacillus species have been reported in immunocompromised patients [79-81]. Lactobacillus endocarditis has been reported in an otherwise healthy patient taking a probiotic formulation containing Lactobacillus [82]. Moreover, there are substantial concerns about the transfer of resistance genes among probiotics, pathogens, and gut microbiota through horizontal gene transfer and the adverse potential of probiotics as the source of antimicrobial resistance genes [83,84]. Thus, the clinical application of probiotics for decreasing Enterobacterales gut carriage among patients with an immunocom- 
promised status should consider the possibility of opportunistic infections caused by these probiotic strains.

\section{Conclusions}

The rationale for using probiotic supplements to eradicate gut Enterobacterales carriage includes changes in the microbiota and metabolomes, nutrition competition, and the secretion of antimicrobial proteins to establish a gut environment that is not friendly to Enterobacterales. Many probiotics indeed do show Enterobacterales-inhibiting effects ex vivo and in vivo. In livestock, probiotics have been widely used to eradicate colonic or environmental Enterobacterales colonization for years, either administered by oral supplementation, in ovo use, or used as environmental disinfectants. For humans, probiotics have been used as dietary supplements for infants to decease potentially pathogenic Enterobacterales in the gut, and probiotics mixtures have shown promising results. This encouraging effect of probiotics on decreasing the gut carriage of Enterobacterales is likely related to the simple gut microbiota in infants, and less interference from underlying chronic diseases and prior antimicrobial exposure.

In contrast to the beneficial effects in infants, for adults, probiotic supplements might decrease potentially pathogenic Enterobacterales in the gut, but they fail to eradicate them. More efforts to confront dysbiosis resulting from comorbidities or antimicrobial therapy, and to select multifunctional probiotics or synbiotics to improve gut health in elderly patients with complex health problems, are currently required.

Author Contributions: Y.-P.H., P.-J.T. and W.-C.K. designed the manuscript structure; C.-C.L., Y.-P.H., and J.-C.L. performed the literature review and participated in the writing of the manuscript; P.-J.T., P.-R.H. and W.-C.K. edited and approved the final version of the manuscript. All authors have read and agreed to the published version of the manuscript.

Funding: This research was funded by Ministry of Science and Technology, Taiwan (grant number MOST 109-2314-B-006-089-MY3 and 110-2314-B-675-001).

Institutional Review Board Statement: The approval by Institutional Review Board is waived due to the article nature of review article.

Informed Consent Statement: Not applicable for studies not involving humans.

Data Availability Statement: Not applicable since this work did not report experimental data.

Conflicts of Interest: All authors report no conflicts of interest relevant to this article.

\section{References}

1. Greer, R.; Dong, X.; Morgun, A.; Shulzhenko, N. Investigating a holobiont: Microbiota perturbations and transkingdom networks. Gut Microbes 2016, 7, 126-135. [CrossRef]

2. Santoro, A.; Zhao, J.; Wu, L.; Carru, C.; Biagi, E.; Franceschi, C. Microbiomes other than the gut: Inflammaging and age-related diseases. Semin. Immunopathol. 2020, 42, 589-605. [CrossRef] [PubMed]

3. Ochman, H.; Worobey, M.; Kuo, C.H.; Ndjango, J.B.; Peeters, M.; Hahn, B.H.; Hugenholtz, P. Evolutionary relationships of wild hominids recapitulated by gut microbial communities. PLoS Biol. 2010, 8, e1000546. [CrossRef] [PubMed]

4. El Kafsi, H.; Gorochov, G.; Larsen, M. Host genetics affect microbial ecosystems via host immunity. Curr. Opin. Allergy Clin. Immunol. 2016, 16, 413-420. [CrossRef] [PubMed]

5. Ghosh, S.; Pramanik, S. Structural diversity, functional aspects and future therapeutic applications of human gut microbiome. Arch. Microbiol. 2021, 10. [CrossRef]

6. Grech, A.; Collins, C.E.; Holmes, A.; Lal, R.; Duncanson, K.; Taylor, R.; Gordon, A. Maternal exposures and the infant gut microbiome: A systematic review with meta-analysis. Gut Microbes 2021, 13, 1-30. [CrossRef]

7. Yang, B.; Chen, Y.; Stanton, C.; Ross, R.P.; Lee, Y.K.; Zhao, J.; Zhang, H.; Chen, W. Bifidobacterium and Lactobacillus Composition at Species Level and Gut Microbiota Diversity in Infants before 6 Weeks. Int. J. Mol. Sci. 2019, 20, 3306. [CrossRef]

8. Rivard-Yazigi, L.; Zahar, J.R.; Le Guillou, S.; Chalouhi, C.; Lecuyer, H.; Bureau, C.; Nassif, X.; Gendrel, D.; Abadie, V. Risk factors associated with extended-spectrum beta-lactamase-producing Enterobacteriaceae carriage at admission in an infant cohort at a tertiary teaching hospital in France. Am. J. Infect. Control 2013, 41, 844-845. [CrossRef] 
9. Hurrell, E.; Kucerova, E.; Loughlin, M.; Caubilla-Barron, J.; Hilton, A.; Armstrong, R.; Smith, C.; Grant, J.; Shoo, S.; Forsythe, S. Neonatal enteral feeding tubes as loci for colonisation by members of the Enterobacteriaceae. BMC Infect. Dis. $2009,9,146$. [CrossRef]

10. Yasmin, F.; Tun, H.M.; Konya, T.B.; Guttman, D.S.; Chari, R.S.; Field, C.J.; Becker, A.B.; Mandhane, P.J.; Turvey, S.E.; Subbarao, P.; et al. Cesarean Section, Formula Feeding, and Infant Antibiotic Exposure: Separate and Combined Impacts on Gut Microbial Changes in Later Infancy. Front. Pediatr. 2017, 5, 200. [CrossRef]

11. Rondanelli, M.; Giacosa, A.; Faliva, M.A.; Perna, S.; Allieri, F.; Castellazzi, A.M. Review on microbiota and effectiveness of probiotics use in older. World J. Clin. Cases 2015, 3, 156-162. [CrossRef] [PubMed]

12. Korach-Rechtman, H.; Hreish, M.; Fried, C.; Gerassy-Vainberg, S.; Azzam, Z.S.; Kashi, Y.; Berger, G. Intestinal Dysbiosis in Carriers of Carbapenem-Resistant Enterobacteriaceae. mSphere 2020, 5. [CrossRef] [PubMed]

13. Piewngam, P.; Quinones, M.; Thirakittiwatthana, W.; Yungyuen, T.; Otto, M.; Kiratisin, P. Composition of the intestinal microbiota in extended-spectrum beta-lactamase-producing Enterobacteriaceae carriers and non-carriers in Thailand. Int. J. Antimicrob. Agents 2019, 53, 435-441. [CrossRef] [PubMed]

14. Lin, T.C.; Hung, Y.P.; Lin, W.T.; Dai, W.; Huang, Y.L.; Ko, W.C. Risk factors and clinical impact of bacteremia due to carbapenemnonsusceptible Enterobacteriaceae: A multicenter study in southern Taiwan. J. Microbiol. Immunol. Infect. 2021. [CrossRef] [PubMed]

15. Kunishima, H.; Ishibashi, N.; Wada, K.; Oka, K.; Takahashi, M.; Yamasaki, Y.; Aoyagi, T.; Takemura, H.; Kitagawa, M.; Kaku, $\mathrm{M}$. The effect of gut microbiota and probiotic organisms on the properties of extended spectrum beta-lactamase producing and carbapenem resistant Enterobacteriaceae including growth, beta-lactamase activity and gene transmissibility. J. Infect. Chemother. 2019, 25, 894-900. [CrossRef] [PubMed]

16. Catho, G.; Huttner, B.D. Strategies for the eradication of extended-spectrum beta-lactamase or carbapenemase-producing Enterobacteriaceae intestinal carriage. Expert Rev. Anti-Infect. Ther. 2019, 17, 557-569. [CrossRef]

17. Weng, Y.J.; Jiang, D.X.; Liang, J.; Ye, S.C.; Tan, W.K.; Yu, C.Y.; Zhou, Y. Effects of Pretreatment with Bifidobacterium bifidum Using 16S Ribosomal RNA Gene Sequencing in a Mouse Model of Acute Colitis Induced by Dextran Sulfate Sodium. Med. Sci. Monit. 2021, 27, e928478. [CrossRef]

18. Chen, L.; Li, H.; Chen, Y.; Yang, Y. Probiotic Lactobacillus rhamnosus GG reduces mortality of septic mice by modulating gut microbiota composition and metabolic profiles. Nutrition 2020, 78, 110863. [CrossRef]

19. Sasaki, K.; Sasaki, D.; Inoue, J.; Hoshi, N.; Maeda, T.; Yamada, R.; Kondo, A. Bacillus coagulans SANK 70258 suppresses Enterobacteriaceae in the microbiota of ulcerative colitis in vitro and enhances butyrogenesis in healthy microbiota. Appl. Microbiol. Biotechnol. 2020, 104, 3859-3867. [CrossRef]

20. Yi, R.; Tan, F.; Liao, W.; Wang, Q.; Mu, J.; Zhou, X.; Yang, Z.; Zhao, X. Isolation and Identification of Lactobacillus plantarum HFY05 from Natural Fermented Yak Yogurt and Its Effect on Alcoholic Liver Injury in Mice. Microorganisms 2019, 7, 530. [CrossRef]

21. Whittemore, J.C.; Stokes, J.E.; Price, J.M.; Suchodolski, J.S. Effects of a synbiotic on the fecal microbiome and metabolomic profiles of healthy research cats administered clindamycin: A randomized, controlled trial. Gut Microbes 2019, 10, 521-539. [CrossRef]

22. Park, H.E.; Kim, Y.J.; Do, K.H.; Kim, J.K.; Ham, J.S.; Lee, W.K. Effects of Queso Blanco Cheese Containing Bifidobacterium longum KACC 91563 on the Intestinal Microbiota and Short Chain Fatty Acid in Healthy Companion Dogs. Korean J. Food Sci. Anim. Resour. 2018, 38, 1261-1272. [CrossRef]

23. Chen, L.; Li, H.; Li, J.; Chen, Y.; Yang, Y. Lactobacillus rhamnosus GG treatment improves intestinal permeability and modulates microbiota dysbiosis in an experimental model of sepsis. Int. J. Mol. Med. 2019, 43, 1139-1148. [CrossRef]

24. Berreta, A.; Kopper, J.J.; Alexander, T.L.; Kogan, C.J.; Burbick, C.R. Effect of an In Vitro Proximal Gastrointestinal Tract on Viability of Commercially Available Equine Probiotics. J. Equine Vet. Sci. 2021, 104, 103671. [CrossRef] [PubMed]

25. Raghuvanshi, R.; Grayson, A.G.; Schena, I.; Amanze, O.; Suwintono, K.; Quinn, R.A. Microbial Transformations of Organically Fermented Foods. Metabolites 2019, 9, 165. [CrossRef]

26. Cavalheiro, C.P.; Ruiz-Capillas, C.; Herrero, A.M.; Jimenez-Colmenero, F.; Pintado, T.; de Menezes, C.R.; Fries, L.L.M. Effect of different strategies of Lactobacillus plantarum incorporation in chorizo sausages. J. Sci. Food Agric. 2019, 99, 6706-6712 [CrossRef] [PubMed]

27. Linninge, C.; Xu, J.; Bahl, M.I.; Ahrne, S.; Molin, G. Lactobacillus fermentum and Lactobacillus plantarum increased gut microbiota diversity and functionality, and mitigated Enterobacteriaceae, in a mouse model. Benef. Microbes 2019, 10, 413-424. [CrossRef] [PubMed]

28. Touchefeu, Y.; Montassier, E.; Nieman, K.; Gastinne, T.; Potel, G.; Bruley des Varannes, S.; Le Vacon, F.; de La Cochetiere, M.F. Systematic review: The role of the gut microbiota in chemotherapy- or radiation-induced gastrointestinal mucositis-Current evidence and potential clinical applications. Aliment. Pharmacol. Ther. 2014, 40, 409-421. [CrossRef]

29. Yamashiro, Y.; Nagata, S. Beneficial microbes for premature infants, and children with malignancy undergoing chemotherapy. Benef. Microbes 2010, 1, 357-365. [CrossRef] [PubMed]

30. He, D.; Wang, H.Y.; Feng, J.Y.; Zhang, M.M.; Zhou, Y.; Wu, X.T. Use of pro-/synbiotics as prophylaxis in patients undergoing colorectal resection for cancer: A meta-analysis of randomized controlled trials. Clin. Res. Hepatol. Gastroenterol. 2013, 37, 406-415. [CrossRef] [PubMed]

31. Saliu, E.M.; Ren, H.; Boroojeni, F.G.; Zentek, J.; Vahjen, W. The Impact of Direct-Fed Microbials and Phytogenic Feed Additives on Prevalence and Transfer of Extended-Spectrum Beta-Lactamase Genes in Broiler Chicken. Microorganisms 2020, 8, 322. [CrossRef] 
32. Rodrigues, D.R.; Wilson, K.M.; Trombetta, M.; Briggs, W.N.; Duff, A.F.; Chasser, K.M.; Bottje, W.G.; Bielke, L. A Proteomic View of the Cross-Talk Between Early Intestinal Microbiota and Poultry Immune System. Front. Physiol. 2020, 11, 20. [CrossRef] [PubMed]

33. Chang, C.H.; Teng, P.Y.; Lee, T.T.; Yu, B. Effects of multi-strain probiotic supplementation on intestinal microbiota, tight junctions, and inflammation in young broiler chickens challenged with Salmonella enterica subsp. enterica. Asian-Australas. J. Anim. Sci. 2020, 33, 1797-1808. [CrossRef]

34. Luise, D.; Bertocchi, M.; Motta, V.; Salvarani, C.; Bosi, P.; Luppi, A.; Fanelli, F.; Mazzoni, M.; Archetti, I.; Maiorano, G.; et al. Bacillus sp. probiotic supplementation diminish the Escherichia coli F4ac infection in susceptible weaned pigs by influencing the intestinal immune response, intestinal microbiota and blood metabolomics. J. Anim. Sci. Biotechnol. 2019, 10, 74. [CrossRef]

35. Nakphaichit, M.; Sobanbua, S.; Siemuang, S.; Vongsangnak, W.; Nakayama, J.; Nitisinprasert, S. Protective effect of Lactobacillus reuteri KUB-AC5 against Salmonella Enteritidis challenge in chickens. Benef. Microbes 2019, 10, 43-54. [CrossRef] [PubMed]

36. Zhou, Y.; Ni, X.; Wen, B.; Duan, L.; Sun, H.; Yang, M.; Zou, F.; Lin, Y.; Liu, Q.; Zeng, Y.; et al. Appropriate dose of Lactobacillus buchneri supplement improves intestinal microbiota and prevents diarrhoea in weaning Rex rabbits. Benef. Microbes 2018, 9 , 401-416. [CrossRef] [PubMed]

37. Arreguin-Nava, M.A.; Graham, B.D.; Adhikari, B.; Agnello, M.; Selby, C.M.; Hernandez-Velasco, X.; Vuong, C.N.; Solis-Cruz, B.; Hernandez-Patlan, D.; Latorre, J.D.; et al. Evaluation of in ovo Bacillus spp. based probiotic administration on horizontal transmission of virulent Escherichia coli in neonatal broiler chickens. Poult. Sci. 2019, 98, 6483-6491. [CrossRef]

38. Wilson, K.M.; Rodrigues, D.R.; Briggs, W.N.; Duff, A.F.; Chasser, K.M.; Bielke, L.R. Evaluation of the impact of in ovo administered bacteria on microbiome of chicks through 10 days of age. Poult. Sci. 2019, 98, 5949-5960. [CrossRef]

39. Slizewska, K.; Chlebicz, A. Synbiotics impact on dominant faecal microbiota and short-chain fatty acids production in sows. FEMS Microbiol. Lett. 2019, 366, i133-i146. [CrossRef]

40. Villagran-de la Mora, Z.; Nuno, K.; Vazquez-Paulino, O.; Avalos, H.; Castro-Rosas, J.; Gomez-Aldapa, C.; Angulo, C.; Ascencio, F.; Villarruel-Lopez, A. Effect of a Synbiotic Mix on Intestinal Structural Changes, and Salmonella Typhimurium and Clostridium Perfringens Colonization in Broiler Chickens. Animals 2019, 9, 777. [CrossRef]

41. Veljovic, K.; Dinic, M.; Lukic, J.; Mihajlovic, S.; Tolinacki, M.; Zivkovic, M.; Begovic, J.; Mrvaljevic, I.; Golic, N.; Terzic-Vidojevic, A. Promotion of Early Gut Colonization by Probiotic Intervention on Microbiota Diversity in Pregnant Sows. Front. Microbiol. 2017, 8, 2028. [CrossRef] [PubMed]

42. Ren, H.; Vahjen, W.; Dadi, T.; Saliu, E.M.; Boroojeni, F.G.; Zentek, J. Synergistic Effects of Probiotics and Phytobiotics on the Intestinal Microbiota in Young Broiler Chicken. Microorganisms 2019, 7, 684. [CrossRef] [PubMed]

43. De Cesare, A.; Caselli, E.; Lucchi, A.; Sala, C.; Parisi, A.; Manfreda, G.; Mazzacane, S. Impact of a probiotic-based cleaning product on the microbiological profile of broiler litters and chicken caeca microbiota. Poult. Sci. 2019, 98, 3602-3610. [CrossRef]

44. Marti, M.; Spreckels, J.E.; Ranasinghe, P.D.; Wejryd, E.; Marchini, G.; Sverremark-Ekstrom, E.; Jenmalm, M.C.; Abrahamsson, T. Effects of Lactobacillus reuteri supplementation on the gut microbiota in extremely preterm infants in a randomized placebocontrolled trial. Cell Rep. Med. 2021, 2, 100206. [CrossRef]

45. Wieers, G.; Verbelen, V.; Van Den Driessche, M.; Melnik, E.; Vanheule, G.; Marot, J.C.; Cani, P.D. Do Probiotics During In-Hospital Antibiotic Treatment Prevent Colonization of Gut Microbiota With Multi-Drug-Resistant Bacteria? A Randomized PlaceboControlled Trial Comparing Saccharomyces to a Mixture of Lactobacillus, Bifidobacterium, and Saccharomyces. Front. Public Health 2020, 8, 578089. [CrossRef]

46. Zhou, Y.; Ni, X.; Duan, L.; Niu, L.; Liu, Q.; Zeng, Y.; Wang, Q.; Wang, J.; Khalique, A.; Pan, K.; et al. Lactobacillus plantarum BSGP201683 Improves the Intestinal Barrier of Giant Panda Microbiota-Associated Mouse Infected by Enterotoxigenic Escherichia coli K88. Probiotics Antimicrob. Proteins 2021, 13, 664-676. [CrossRef]

47. Ljungquist, O.; Kampmann, C.; Resman, F.; Riesbeck, K.; Tham, J. Probiotics for intestinal decolonization of ESBL-producing Enterobacteriaceae: A randomized, placebo-controlled clinical trial. Clin. Microbiol. Infect. 2020, 26, 456-462. [CrossRef]

48. Nguyen, M.; Holdbrooks, H.; Mishra, P.; Abrantes, M.A.; Eskew, S.; Garma, M.; Oca, C.G.; McGuckin, C.; Hein, C.B.; Mitchell, R.D.; et al. Impact of Probiotic B. infantis EVC001 Feeding in Premature Infants on the Gut Microbiome, Nosocomially Acquired Antibiotic Resistance, and Enteric Inflammation. Front. Pediatr. 2021, 9, 618009. [CrossRef]

49. Ramos-Ramos, J.C.; Lazaro-Perona, F.; Arribas, J.R.; Garcia-Rodriguez, J.; Mingorance, J.; Ruiz-Carrascoso, G.; Borobia, A.M.; Pano-Pardo, J.R.; Herruzo, R.; Arnalich, F. Proof-of-concept trial of the combination of lactitol with Bifidobacterium bifidum and Lactobacillus acidophilus for the eradication of intestinal OXA-48-producing Enterobacteriaceae. Gut Pathog. 2020, 12, 15. [CrossRef]

50. Li, Y.F.; Zhu, C.R.; Gong, X.L.; Li, H.L.; Xiong, L.K.; Wang, K.J.; Liu, G.S. Beneficial Effects of Probiotic Treatment on Gut Microbiota in Very Low Birth Weight Infants. Gastroenterol. Res. Pract. 2019, 2019, 3682836. [CrossRef]

51. Ishizeki, S.; Sugita, M.; Takata, M.; Yaeshima, T. Effect of administration of bifidobacteria on intestinal microbiota in low-birthweight infants and transition of administered bifidobacteria: A comparison between one-species and three-species administration. Anaerobe 2013, 23, 38-44. [CrossRef] [PubMed]

52. Powell, W.T.; Borghese, R.A.; Kalanetra, K.M.; Mirmiran, M.; Mills, D.A.; Underwood, M.A. Probiotic Administration in Infants With Gastroschisis: A Pilot Randomized Placebo-Controlled Trial. J. Pediatr. Gastroenterol. Nutr. 2016, 62, 852-857. [CrossRef]

53. Wang, C.; Nagata, S.; Asahara, T.; Yuki, N.; Matsuda, K.; Tsuji, H.; Takahashi, T.; Nomoto, K.; Yamashiro, Y. Intestinal Microbiota Profiles of Healthy Pre-School and School-Age Children and Effects of Probiotic Supplementation. Ann. Nutr. Metab. 2015, 67, 257-266. [CrossRef] [PubMed] 
54. Wu, B.B.; Yang, Y.; Xu, X.; Wang, W.P. Effects of Bifidobacterium supplementation on intestinal microbiota composition and the immune response in healthy infants. World J. Pediatr. 2016, 12, 177-182. [CrossRef] [PubMed]

55. Savino, F.; Fornasero, S.; Ceratto, S.; De Marco, A.; Mandras, N.; Roana, J.; Tullio, V.; Amisano, G. Probiotics and gut health in infants: A preliminary case-control observational study about early treatment with Lactobacillus reuteri DSM 17938. Clin. Chim. Acta 2015, 451, 82-87. [CrossRef]

56. Umenai, T.; Shime, N.; Asahara, T.; Nomoto, K.; Itoi, T. A pilot study of Bifidobacterium breve in neonates undergoing surgery for congenital heart disease. J. Intensive Care 2014, 2, 36. [CrossRef] [PubMed]

57. Mohan, R.; Koebnick, C.; Schildt, J.; Schmidt, S.; Mueller, M.; Possner, M.; Radke, M.; Blaut, M. Effects of Bifidobacterium lactis Bb12 supplementation on intestinal microbiota of preterm infants: A double-blind, placebo-controlled, randomized study. J. Clin. Microbiol. 2006, 44, 4025-4031. [CrossRef]

58. Chrzanowska-Liszewska, D.; Seliga-Siwecka, J.; Kornacka, M.K. The effect of Lactobacillus rhamnosus GG supplemented enteral feeding on the microbiotic flora of preterm infants-double blinded randomized control trial. Early Hum. Dev. 2012, 88, 57-60. [CrossRef]

59. Szajewska, H.; Guandalini, S.; Morelli, L.; Van Goudoever, J.B.; Walker, A. Effect of Bifidobacterium animalis subsp lactis supplementation in preterm infants: A systematic review of randomized controlled trials. J. Pediatr. Gastroenterol. Nutr. 2010, 51, 203-209. [CrossRef] [PubMed]

60. La-Ongkham, O.; Nakphaichit, M.; Leelavatcharamas, V.; Keawsompong, S.; Nitisinprasert, S. Distinct gut microbiota of healthy children from two different geographic regions of Thailand. Arch. Microbiol. 2015, 197, 561-573. [CrossRef] [PubMed]

61. Dall, L.B.; Lausch, K.R.; Gedebjerg, A.; Fuursted, K.; Storgaard, M.; Larsen, C.S. Do probiotics prevent colonization with multiresistant Enterobacteriaceae during travel? A randomized controlled trial. Travel Med. Infect. Dis. 2019, 27, 81-86. [CrossRef] [PubMed]

62. Arnbjerg, C.J.; Vestad, B.; Hov, J.R.; Pedersen, K.K.; Jespersen, S.; Johannesen, H.H.; Holm, K.; Halvorsen, B.; Fallentin, E.; Hansen, A.E.; et al. Effect of Lactobacillus rhamnosus GG Supplementation on Intestinal Inflammation Assessed by PET/MRI Scans and Gut Microbiota Composition in HIV-Infected Individuals. J. Acquir. Immune Defic. Syndr. 2018, 78, 450-457. [CrossRef]

63. Nagino, T.; Kaga, C.; Kano, M.; Masuoka, N.; Anbe, M.; Moriyama, K.; Maruyama, K.; Nakamura, S.; Shida, K.; Miyazaki, K. Effects of fermented soymilk with Lactobacillus casei Shirota on skin condition and the gut microbiota: A randomised clinical pilot trial. Benef. Microbes 2018, 9, 209-218. [CrossRef] [PubMed]

64. Bajaj, J.S.; Heuman, D.M.; Hylemon, P.B.; Sanyal, A.J.; Puri, P.; Sterling, R.K.; Luketic, V.; Stravitz, R.T.; Siddiqui, M.S.; Fuchs, M.; et al. Randomised clinical trial: Lactobacillus GG modulates gut microbiome, metabolome and endotoxemia in patients with cirrhosis. Aliment. Pharmacol. Ther. 2014, 39, 1113-1125. [CrossRef]

65. Larsen, N.; Vogensen, F.K.; Gobel, R.J.; Michaelsen, K.F.; Forssten, S.D.; Lahtinen, S.J.; Jakobsen, M. Effect of Lactobacillus salivarius Ls-33 on fecal microbiota in obese adolescents. Clin. Nutr. 2013, 32, 935-940. [CrossRef]

66. Mangell, P.; Thorlacius, H.; Syk, I.; Ahrne, S.; Molin, G.; Olsson, C.; Jeppsson, B. Lactobacillus plantarum 299v does not reduce enteric bacteria or bacterial translocation in patients undergoing colon resection. Dig. Dis. Sci. 2012, 57, 1915-1924. [CrossRef]

67. Oudhuis, G.J.; Bergmans, D.C.; Dormans, T.; Zwaveling, J.H.; Kessels, A.; Prins, M.H.; Stobberingh, E.E.; Verbon, A. Probiotics versus antibiotic decontamination of the digestive tract: Infection and mortality. Intensive Care Med. 2011, 37, 110-117. [CrossRef]

68. Reddy, B.S.; Macfie, J.; Gatt, M.; Larsen, C.N.; Jensen, S.S.; Leser, T.D. Randomized clinical trial of effect of synbiotics, neomycin and mechanical bowel preparation on intestinal barrier function in patients undergoing colectomy. Br. J. Surg. 2007, 94, 546-554. [CrossRef] [PubMed]

69. More, M.I.; Swidsinski, A. Saccharomyces boulardii CNCM I-745 supports regeneration of the intestinal microbiota after diarrheic dysbiosis-A review. Clin. Exp. Gastroenterol. 2015, 8, 237-255. [CrossRef]

70. Andrejcakova, Z.; Sopkova, D.; Vlckova, R.; Hertelyova, Z.; Gancarcikova, S.; Nemcova, R. The Application of Lactobacillus reuteri CCM 8617 and Flaxseed Positively Improved the Health of Mice Challenged with Enterotoxigenic E. coli O149:F4. Probiotics Antimicrob. Proteins 2020, 12, 937-951. [CrossRef]

71. Sassone-Corsi, M.; Nuccio, S.P.; Liu, H.; Hernandez, D.; Vu, C.T.; Takahashi, A.A.; Edwards, R.A.; Raffatellu, M. Microcins mediate competition among Enterobacteriaceae in the inflamed gut. Nature 2016, 540, 280-283. [CrossRef]

72. Litvak, Y.; Mon, K.K.Z.; Nguyen, H.; Chanthavixay, G.; Liou, M.; Velazquez, E.M.; Kutter, L.; Alcantara, M.A.; Byndloss, M.X.; Tiffany, C.R.; et al. Commensal Enterobacteriaceae Protect against Salmonella Colonization through Oxygen Competition. Cell Host Microbe 2019, 25, 128-139. [CrossRef]

73. D'Inca, R.; Barollo, M.; Scarpa, M.; Grillo, A.R.; Brun, P.; Vettorato, M.G.; Castagliuolo, I.; Sturniolo, G.C. Rectal administration of Lactobacillus casei DG modifies flora composition and Toll-like receptor expression in colonic mucosa of patients with mild ulcerative colitis. Dig. Dis. Sci. 2011, 56, 1178-1187. [CrossRef]

74. Palmer, J.D.; Piattelli, E.; McCormick, B.A.; Silby, M.W.; Brigham, C.J.; Bucci, V. Engineered Probiotic for the Inhibition of Salmonella via Tetrathionate-Induced Production of Microcin H47. ACS Infect. Dis. 2018, 4, 39-45. [CrossRef] [PubMed]

75. Cameron, A.; Zaheer, R.; Adator, E.H.; Barbieri, R.; Reuter, T.; McAllister, T.A. Bacteriocin Occurrence and Activity in Escherichia coli Isolated from Bovines and Wastewater. Toxins 2019, 11, 475. [CrossRef]

76. Underwood, M.A.; German, J.B.; Lebrilla, C.B.; Mills, D.A. Bifidobacterium longum subspecies infantis: Champion colonizer of the infant gut. Pediatr. Res. 2015, 77, 229-235. [CrossRef] [PubMed]

77. Clinicaltrials.gov. Available online: https://clinicaltrials.gov/ct2/home (accessed on 23 August 2021). 
78. Giuffre, M.; Campigotto, M.; Campisciano, G.; Comar, M.; Croce, L.S. A story of liver and gut microbes: How does the intestinal flora affect liver disease? A review of the literature. Am. J. Physiol. Gastrointest. Liver Physiol. 2020, 318, G889-G906. [CrossRef]

79. Vyas, V.; Mian, S.; Paolino, K.; Siddique, Z. Lactobacillus masticator abscess after probiotics consumption. Bayl. Univ. Med. Cent. Proc. 2020, 34, 93-94. [CrossRef]

80. Chiang, M.C.; Chen, C.L.; Feng, Y.; Chen, C.C.; Lien, R.; Chiu, C.H. Lactobacillus rhamnosus sepsis associated with probiotic therapy in an extremely preterm infant: Pathogenesis and a review for clinicians. J. Microbiol. Immunol. Infect. 2020, 54, 575-580. [CrossRef] [PubMed]

81. Sendil, S.; Shrimanker, I.; Mansoora, Q.; Goldman, J.; Nookala, V.K. Lactobacillus rhamnosus Bacteremia in an Immunocompromised Renal Transplant Patient. Cureus 2020, 12, e6887. [CrossRef]

82. Pasala, S.; Singer, L.; Arshad, T.; Roach, K. Lactobacillus endocarditis in a healthy patient with probiotic use. IDCases 2020, 22, e00915. [CrossRef] [PubMed]

83. Egervarn, M.; Lindmark, H.; Olsson, J.; Roos, S. Transferability of a tetracycline resistance gene from probiotic Lactobacillus reuteri to bacteria in the gastrointestinal tract of humans. Antonie Van Leeuwenhoek 2010, 97, 189-200. [CrossRef] [PubMed]

84. Daniali, M.; Nikfar, S.; Abdollahi, M. Antibiotic resistance propagation through probiotics. Expert Opin. Drug Metab. Toxicol. 2020, 16, 1207-1215. [CrossRef] [PubMed] 